\title{
PREFACE: YOU CAN'T FIX BY ANALYSIS WHAT YOU BUNGLED BY DESIGN
}

We are seeing an explosion of interest in systematic research to improve the effectiveness of college. Parents and students ask what growing tuitions buy. Governors ask how to make public systems of higher education more costeffective. Presidents and deans ask how they can attract better prepared students to their schools. Faculty members show a growing interest in innovation. How can teaching be strengthened? What are students learning? How long do students retain what they have learned?

For several years, we have been addressing these and other questions about higher education in the Harvard Seminar on Assessment. Initiated by President Derek Bok, the Seminar involves over one hundred faculty, administrators, and students from twenty colleges and universities. The Seminar gives us a wonderful opportunity to work 
closely with colleagues from other campuses to plan and conduct research on higher education.

Members of the Seminar agreed not only to explore higher education as it stands now but also to work for its improvement. As President Bok wrote in his inaugural letter to Seminar participants:

I am beginning to think about how one might move from an initial stage of arousing interest in assessment and demonstrating its potential to a further stage involving sustained effort to learn how well we are doing and how we can do better in achieving certain major goals of education. My longer-term concerns involve the possibility of devising a research strategy involving a series of studies over time to increase our knowledge of how to achieve some truly fundamental goals of education. Perhaps this is too ambitious an objective. Yet I cannot help thinking that an institution serious about improving the quality of its education should develop some sort of sustained strategy of research along these lines.

Seminar participants adopted, and indeed broadened, Bok's call for systematic research. They identified potential innovations, reviewed what was known already, and then conducted research projects. Participants familiar with organizing research in universities organized their own projects. Others without a formal research background sought the advice of colleagues. The three authors of this book brought our own experience in program evaluation, education, and health policy research to the Seminar, and worked with our colleagues to organize and carry out new projects.

We want to share with a wider audience the lessons we have learned about planning and implementing research in higher education. Our experience is most extensive with projects conducted at institutions participating in the Seminar, but the problems and challenges we faced are common to many of America's colleges and universities. For example, faculty members at nearly every college wish to 
strengthen the clarity and style of expository writing. Faculty members at nearly every college wish to understand the long-run effects of different courses, and what students retain over time, if anything. A core of such basic questions spans many campuses.

This book is written for anyone interested in investigating how American higher education works, and how research can be used to improve it. We try to strike a balance between general principles and specific details, between what we would like in a perfect world and what can be done in the real world, between theory and practice. We are convinced that good research is easier to carry out in higher education than in any other setting. Faculty, staff, and students in our colleges and universities understand the value of research. They are often willing participants in the process. Admissions records make sampling easier. The registrar's office can easily provide background information on participants in a project. Students are accustomed to being evaluated. Individual faculty members, and entire departments, enjoy a pedagogical autonomy that permits them to innovate. There is an all-pervading sense that more information means a better job can be done. Where is there a more supportive arena for high-quality research?

We hope that faculty, administrators, and students will all find this book useful. It requires only a modest technical background. There are no equations; readers need only be familiar with the concepts presented in a basic statistics course. Readers who want to design and implement projects of their own will find practical advice. Readers interested in commissioning research, or interpreting the research of others, will find suggestions about how to distinguish good research from bad.

We emphasize research design over measurement and analysis. This is because good design comes first. No matter how precise your measurement or how sophisticated your analyses, you risk failure if your research is not well 
planned. You can't fix by analysis what you bungled by design. Therefore, we discuss the basic principles of research design and illustrate our points with sixty real examples of recent research in higher education. Our examples come from private and public institutions, two-year and four-year, selective and not so selective colleges.

The book is organized around the questions we ask colleagues who come to us for help in planning their research. What do you want to know? What has been done before on your topic? What can you learn from it? Whom are you interested in studying? What measures will you use? Are they the best measures for this purpose? What predictors interest you? How many students must you include? Should you try out your project on a small scale? Each of these questions gives rise to a chapter in this book.

A key theme throughout is that improving the effectiveness of an institution takes time and requires using the results of research to change policies. Therefore, organizing systematic research at any college is a long-term process. Most of our colleagues pay close attention when an innovation, such as a new way of teaching, is found to work particularly well. Everyone is interested in especially successful outcomes, and in how they were achieved. But a big lesson from our Seminar on Assessment is that by rewarding only successful innovations, a college may create an atmosphere that discourages widespread experimentation. If each of three professors has a new idea for improving instruction, does anyone really expect all three ideas to be major breakthroughs? Of course not. We shouldn't be surprised if one or more of them don't work any better than the old way; indeed, we should be delighted if any of the new methods is an improvement. Yet, often only those colleagues with successful innovations are rewarded. Shouldn't all three professors be encouraged and commended because they tried a new idea and systematically evaluated how well it worked? 
The best way to encourage new ideas and innovation, as well as careful evaluation and assessment of them, is to reward the process of systematic investigation. Administrators and faculty should be urged to try a change in procedure, to compare outcomes achieved with an innovation to outcomes achieved with older methods. This means taking risks. Not all innovations will work. But without risk-taking, and systematic evaluation of its results, innovation and improvement cannot flourish.

Rewarding the evaluation process has yet another strength-it sets the tone that research is an ongoing, cumulative activity, and that one of its benefits is to enhance the college experience for future generations of students. Any one project, whether it tries to improve teaching or to identify and help students who are struggling, is but one step in a long-run effort to strengthen higher education. A long-term policy of systematic innovation and assessment builds in a constant search for improvement, and rewards all those who participate in the search. It is a goal worth working hard to achieve. 
